\title{
Risk factors influencing dentists' hepatitis B-related knowledge and attitudes and their willingness to treat hepatitis $B$ positive patients
}

B. Khosravanifard, ${ }^{7}$ V. Rakhshan, ${ }^{2,3}$ S. Sherafat ${ }^{4}$ and L. Najafi-Salehi ${ }^{4}$

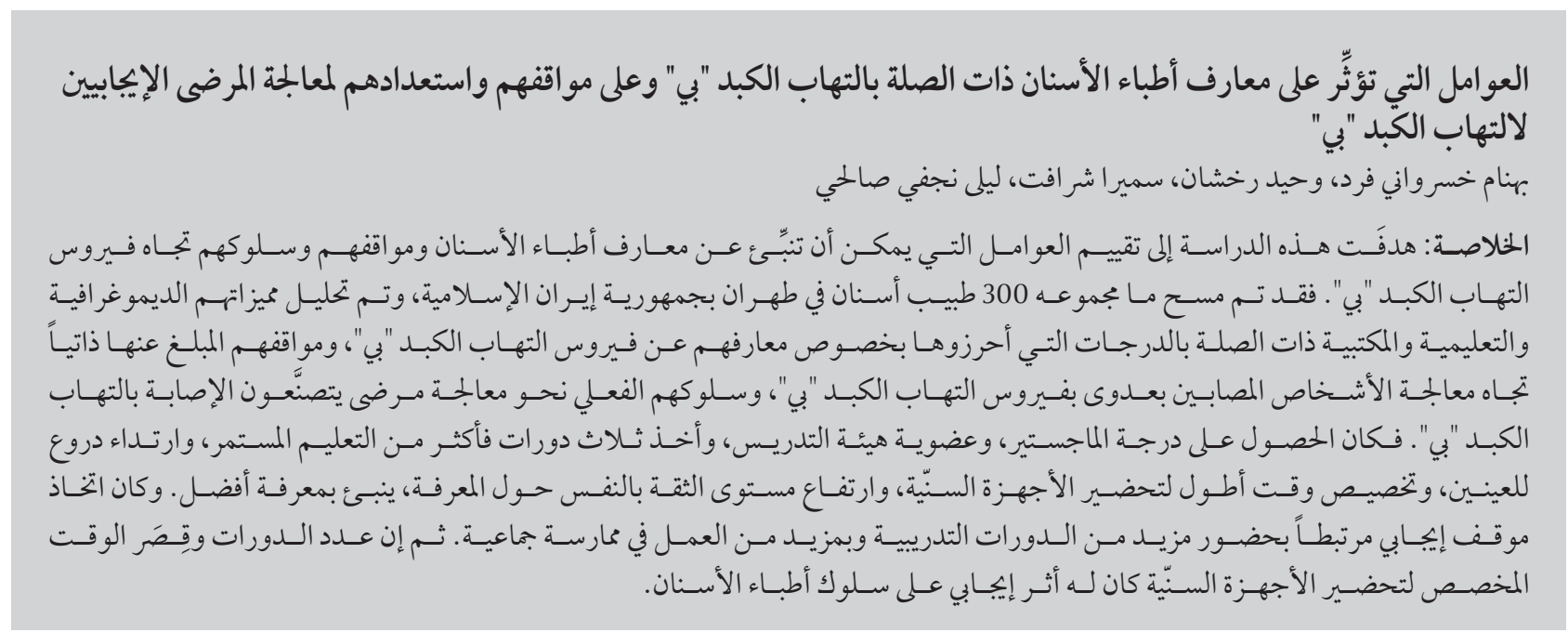

ABSTRACT This study assessed factors that could predict dentists' knowledge, attitudes and behaviour towards hepatitis B virus (HBV). A total of 300 dentists in Tehran, Islamic Republic of Iran were surveyed and their demographic, educational and office characteristics were analysed in relation to their scores on knowledge about HBV, self-reported attitudes towards treating people infected with HBV and actual behaviour towards treating simulated HBV-positive patients. Having a Master's degree, faculty membership, taking $\geq 3$ continuing education courses, wearing eyeshields, spending more time on preparing dental units and higher self-confidence about knowledge predicted better knowledge. A positive attitude was associated with having attended more courses and working in group practice. The number of courses and a shorter dental unit preparation time positively affected dentists' behaviour.

Facteurs de risque influant sur les connaissances des dentistes en matière d'hépatite $B$ et leurs attitudes et volonté de soigner des patients positifs pour l'hépatite B

RÉSUMÉ La présente étude visait à évaluer les facteurs permettant de prédire les connaissances, les attitudes et le comportement des dentistes vis-à-vis du virus d'hépatite B. Au total, 300 dentistes à Téhéran (République islamique d'Iran) ont participé à une enquête tandis que leurs caractéristiques démographiques, académiques et professionnelles ont été analysées en lien avec leurs scores pour les connaissances sur le virus de l'hépatite B, pour leurs attitudes autodéclarées concernant les soins accordés aux personnes infectées par ce virus et pour leur comportement réel de soignant envers les patients ayant prétendu être infectés. Être titulaire d'un diplôme de Master, être membre d'une faculté, avoir suivi au moins trois cours de formation continue, porter des lunettes de sécurité, passer plus de temps à préparer les unités dentaires et avoir davantage d'assurance sur ses connaissances étaient des facteurs prédictifs d'un niveau de connaissances supérieur. Une attitude positive était associée à une participation à davantage de formations et à une activité exercée au sein d'un groupement médical. Le nombre de formations et un temps de préparation de l'unité dentaire plus court influaient positivement sur le comportement des dentistes.

'Department of Orthodontics; ${ }^{3}$ Department of Dental Anatomy and Morphology, Dental Branch, Islamic Azad University, Tehran, Islamic Republic of Iran (Correspondence to V. Rakhshan: vahid.rakhshan@gmail.com). 2Iranian Tissue Bank and Research Centre, Tehran University of Medical Sciences, Tehran, Islamic Republic of Iran. ${ }^{4}$ Private Dental Practice, Tehran, Islamic Republic of Iran.

Received: 29/10/13; accepted: 21/08/14 


\section{Introduction}

Hepatitis B is a serious global public health threat and is estimated to kill about 1 million people annually $(1-5)$. The hepatitis B virus (HBV) is about 50 to 100 times more infectious than HIV (6). This might deter clinicians from treating HBV-positive patients (7), even though it is unethical and in some countries illegal to refuse treatment to HBV patients $(1,8)$. Clinicians' reluctance to treat infected patients could also have serious implications for public health (9); for example, there is a greater risk of cross-contamination if patients conceal their disease status $(1,3,9,10)$.

Despite these issues, many dentists still refuse to treat patients suffering from bloodborne diseases ( 8 ) due to dentists' higher exposure risks than the general public and even other healthcare professionals $(1,2,4,5,7,9,11-14)$. Dentists' unwillingness cannot be tackled by legal penalties ( 8 ) but by improvements in attitude $(9,15,16)$, which might be a reflection of improved knowledge and confidence $(9,10,15,16)$. Factors influencing clinicians' attitude and willingness to treat HBV-positive patients and their knowledge about hepatitis $B$ can be used to improve the quality and ethics of dental practice, to improve patients' lives and to reduce cross-contamination risks. Such information is of value to clinicians, academics and policy-makers worldwide. However, to the best of our knowledge, research into these factors has not been reported before in the English language literature.

In a previous report of the same research, we described Tehran dentists' knowledge about hepatitis and HBV, their self-reported attitudes towards people with HBV and their actual behaviour towards treating simulated HBV-positive patients (7). In this paper, we report the demographic, educational and office factors influencing dentists' knowledge, attitudes and behaviour.

\section{Methods}

\section{Sampling}

This 2-phase cross-sectional study was performed on 300 dentists including 189 general practitioners with a general dentist qualification [Doctor of Dental Medicine (DDM)/Doctor of Dental Surgery (DDS)/Doctor of Medicine in Dentistry (DMD)] and 111 specialists with a Master of Science in Dentistry (MSD), who were randomly selected from the more than 6000 dentists practising in Tehran. A total of 392 dentists were selected and visited and/ or called until the desired sample size was reached. The inclusion criterion was practising dentistry in Tehran. The exclusion criteria were not being available at the scheduled session or refusal to participate in the second session (92 dentists were excluded). Each included dentist $(n=300)$ participated in both phases of the study. More details about the sampling are given in our earlier report (7).

Dentists could state their refusal to participate at any time and they would be excluded. No personal identifiers or occupational data were collected. Ethical approval for the study was obtained from the internal review board of the institution.

\section{Data collection}

\section{First phase: evaluation by simulated patients}

In the first phase, dentists' behaviour in terms of their actual willingness to treat patients infected with HBV was directly observed by 2 final-year undergraduate female dental students (aged about 23 years old) who acted as simulated patients. Each observer visited and evaluated 150 dentists. At the time of registration and before the dental examination, the observers declared that they were bloodborne HBV-positive. Afterwards the dentists' reactions were recorded (9) and their willingness to treat the simulated patient was scored on a 4-point scale from 0 (absolutely refused) to 4 (absolutely agreed). Further details of the methods have been described elsewhere (7).

\section{Second phase: interviews using knowl- edge and attitude questionnaires}

About 1 week later, each observer visited the dentists who had been surveyed by the other observer, and interviewed them face-to-face regarding their knowledge and attitudes using a structured questionnaire which also collected demographic data and office characteristics.

The knowledge-oriented questionnaire was designed by a panel of experts and included 18 questions regarding diagnostic criteria and management of HBV infection. The maximum obtainable score was 44 . Some questions had a score of 1 and some had higher scores (different weights) (7). The attitude-oriented questionnaire included 13 questions with 4 Likert-scale answers, (scored from 3 to 0 for each question) which represented the extent of dentists' attitudes towards and willingness to participate in treating HBV-positive patients $(7,9)$.

The following data about the dentists were also recorded:

- demographic profile: age; sex; office district (Tehran south, west, east, centre and north, as a proxy for economic status).

- office characteristics: type of office (solo practice usually charging higher fees, or group practice in a clinic with different departments, usually charging patients lower fees, or both); number of personnel working at the office.

- the dentists' self-reported infection control practices, namely: wearing dental masks, latex gloves, dental glasses/eye-shields; estimated time to prepare the dental unit for the next patient; and available sterilization units (autoclave, oven or both) (7). 
- education and experience: qualifications [general dentist (DDM)/ (DDS)/(DMD) versus specialist (MSD)]; work experience ( $<6$ years versus $\geq 6$ years); university teaching experience (faculty membership); location of graduation (Iranian or foreign university); number of continuing education courses attended $(0,<3$ or $\geq 3)$; time elapsed from last continuing education course $(8,9)$.

- self-confidence: self-rated knowledge of hepatitis B (rated on a 4-point Likert scale from very poor to very good).

- major source of information regarding hepatitis B (books, articles, media, classes).

- vaccination status: completed 3-course HBV vaccination; checked hepatitis B surface antigen antibody (antiHBs) status.

\section{Statistical analysis}

For the risk-factor analyses, bivariate and multivariate analyses were performed. Data were missing regarding the country of education in MSD programmes as most dentists only had a general dentistry degree; thus this variable was excluded from the multivariate models in order to avoid decreasing the sample size to 111 cases; its effect was assessed (along with the effects of other variables) only using Spearman correlation coefficient. Predictors of knowledge and attitude (their total scores entered as continuous variables) were analysed using stepwise and single-model linear regression analysis. Behaviour predictors were modelled in an ordinal logistic regression. The behaviour score was also dichotomized into agreeing to treat and not agreeing to treat the simulated patient (7) and the association of the independent variables with the binary behaviour scores were assessed using binary logistic regression.

The statistical software used was SPSS, version 20.0. The level of significance was set at $P \leq 0.05$.

\section{Results}

The mean age of participants was 43.9 (SD 7.3) years, and 211 (70.3\%) of them were males. The educational and occupational characteristics of the sample are reported in our earlier paper (7). Briefly, 19.3\% had graduated from foreign universities with a general dentistry qualification and $7.0 \%$ were foreign graduates with a specialist (Master's) degree, $83.3 \%$ had $>6$ years of clinical experience, $19.7 \%$ had academic teaching experience, $38.7 \%$ had attended continuing education courses $>3$ times and $41.3 \%$ had attended such courses within the previous 2 years. Of the participants, $88.3 \%$ had been vaccinated against hepatitis B but only $55.0 \%$ had had their antibody titre tested.

No significant correlations were found between the dentists' place of graduate education and any of the dependent variables (Spearman coefficient, all $P$ values $>0.5)$ (Table 1$)$. The Spearman correlation coefficient indicated significant associations between dentists' knowledge and the following variables: MS degree; number of continuing education courses attended; duration since last course; faculty membership; time assigned to prepare the dental chair/unit for patients; using eye-shields; and vaccination status. The only variable that significantly correlated with attitude was the number of courses attended. Behaviour was correlated (negatively) only with being vaccinated (Table 1 ).

\section{Knowledge}

Overall, the mean knowledge score of dentists was $32.1 \%$ (SD 15.7\%) of the highest possible score. All the variables including attitude and knowledge were modelled in a backward-selection multiple regression analysis. The final regression model identified 5 predictors for knowledge (adjusted $R^{2}=0.115, F=$ 8.739, $P<0.001$ ) (Table 2): having an MSD degree; attended $\geq 3$ continuing education courses; having very good self-confidence concerning knowledge of hepatitis B; using eye-shield/glasses; and time taken to prepare the dental unit for each patient.

A new model was tested with factors that might theoretically affect knowledge: sex; age; degree; place of graduation; experience; faculty membership; number of courses attended; time elapsed since the last course; confidence about knowledge; and sources of information. The model was then manually optimized (adjusted $R^{2}=$ $0.101, F=5.187, P<0.001)$. It identified 3 significant variables: faculty membership; number of courses attended; and self-confidence about knowledge (Table 3).

\section{Attitude}

Overall, the mean attitude score of dentists was 51.2\% (SD 9.3\%) of the highest possible score. All the variables including knowledge and behaviour were entered into the backward-selection multiple regression analysis as potential predictors. The final model which had the greatest adjusted $R^{2}$ value $\left(R^{2}=\right.$ $0.035, F=4.595, P=0.004)$ identified 2 significant predictors for attitude (Table 2): working in group practice; and number of courses attended.

When all the variables (including knowledge and behaviour) were entered into a single regression model, only working in group practice with other dentists was a significant predictor of attitude $(\beta=0.183, P=0.017)$.

\section{Behaviour}

Overall, the mean behaviour score of dentists was 64.3\% (SD 26.7\%) of the highest possible score. All the variables including knowledge and attitude were modelled in a series of backward-selection multiple binary logistic regressions. Dentists who had not received hepatitis B vaccination (compared with those who were vaccinated) (OR 0.38; 95\% CI: 0.16-0.90), those who had had their titres tested (OR 2.31; 95\% CI: 1.35-3.96), and clinicians who had 


\begin{tabular}{|c|c|c|c|c|c|c|}
\hline \multirow[t]{2}{*}{ Independent variable } & \multicolumn{2}{|c|}{ Knowledge $^{a}$} & \multicolumn{2}{|c|}{ Attitudes $^{\text {b }}$} & \multicolumn{2}{|c|}{ Behaviour $^{\mathrm{c}}$} \\
\hline & $\rho$ & $P$-value & $\rho$ & $P$-value & $\rho$ & $P$-value \\
\hline \multicolumn{7}{|l|}{ Demographic data } \\
\hline Sex: male & -0.044 & 0.443 & 0.023 & 0.694 & 0.037 & 0.526 \\
\hline Age: older & 0.022 & 0.704 & 0.105 & 0.070 & 0.062 & 0.283 \\
\hline Practice location & -0.048 & 0.407 & -0.048 & 0.410 & -0.041 & 0.481 \\
\hline \multicolumn{7}{|l|}{ Educational characteristics } \\
\hline Degree: MSD & 0.169 & 0.003 & 0.068 & 0.241 & -0.105 & 0.069 \\
\hline Study origin: abroad & -0.111 & 0.056 & -0.025 & 0.671 & 0.060 & 0.301 \\
\hline No. of continuing education courses: $\geq 3$ & 0.185 & 0.001 & 0.151 & 0.009 & 0.105 & 0.069 \\
\hline Last course date: $\geq 2 \mathrm{yr}$ & -0.163 & 0.005 & -0.103 & 0.076 & -0.029 & 0.621 \\
\hline Specialty origin: abroad & 0.036 & 0.708 & 0.005 & 0.958 & -0.051 & 0.593 \\
\hline Experience: $\geq 6 \mathrm{yr}$ & -0.014 & 0.815 & 0.055 & 0.348 & 0.002 & 0.975 \\
\hline Faculty membership: yes & 0.185 & 0.001 & 0.008 & 0.886 & 0.007 & 0.904 \\
\hline \multicolumn{7}{|l|}{ Source of HBV knowledge } \\
\hline Classes: yes & 0.034 & 0.558 & -0.029 & 0.620 & -0.052 & 0.371 \\
\hline Books: yes & -0.002 & 0.974 & -0.050 & 0.385 & 0.030 & 0.600 \\
\hline Articles: yes & 0.007 & 0.898 & 0.083 & 0.149 & 0.044 & 0.443 \\
\hline TV: yes & -0.067 & 0.248 & -0.039 & 0.506 & 0.021 & 0.720 \\
\hline \multicolumn{7}{|l|}{ HBV vaccination history } \\
\hline Vaccinated: yes & 0.122 & 0.034 & -0.047 & 0.416 & -0.123 & 0.032 \\
\hline Titre check: yes & 0.082 & 0.165 & 0.023 & 0.700 & 0.093 & 0.117 \\
\hline \multicolumn{7}{|l|}{ Office characteristics } \\
\hline Solo practice: yes & 0.112 & 0.054 & -0.025 & 0.671 & -0.019 & 0.742 \\
\hline Group practice: yes & -0.059 & 0.307 & 0.106 & 0.066 & -0.073 & 0.205 \\
\hline No. of personnel: higher & -0.002 & 0.969 & -0.047 & 0.432 & 0.087 & 0.144 \\
\hline \multicolumn{7}{|l|}{ Office practices } \\
\hline Preparation time for next patient: longer & 0.120 & 0.042 & 0.016 & 0.787 & -0.136 & 0.021 \\
\hline Use mask: yes & 0.032 & 0.577 & 0.022 & 0.708 & 0.045 & 0.438 \\
\hline Use gloves: yes & 0.011 & 0.853 & 0.092 & 0.111 & -0.021 & 0.717 \\
\hline Use eye-shield: yes & 0.183 & 0.002 & -0.039 & 0.498 & 0.039 & 0.499 \\
\hline Have oven: yes & -0.029 & 0.618 & 0.059 & 0.311 & 0.009 & 0.880 \\
\hline Have autoclave: yes & 0.029 & 0.614 & -0.025 & 0.672 & -0.041 & 0.484 \\
\hline \multicolumn{7}{|l|}{ Self-confidence } \\
\hline Self-rated knowledge about HBV: higher & 0.171 & 0.003 & 0.032 & 0.584 & -0.044 & 0.450 \\
\hline
\end{tabular}

${ }^{a}$ Based on 18 items, higher score indicated better knowledge; ${ }^{b}$ Based on 13 items, higher score indicated better attitudes; ${ }^{c}$ Based on 1 item, dichotomized into willing or unwilling to treat a simulated HBV-positive patient. $M S D=$ Master of science in dentistry.

attended $\geq 3$ continuing education courses (compared with dentists who had attended < 3 courses) (OR 2.15; 95\% CI: 1.26-3.67) were significantly more willing to deliver dental treatment to the HBV-positive simulated patient. Graduates from Iranian universities were significantly more likely to agree to treat patients (compared with dentists who had graduated abroad) (OR 2.08; 95\% CI: 1.06-4.07) (Table 4).

All the variables (including knowledge and attitude) were entered into a multiple ordinal logistic regression. Afterwards, the model was optimized (Table 5). The results showed that clinicians with general dentist qualifications were more likely to treat HBVpositive patients than were specialist dentists with an MSD degree (OR 0.60; 95\% CI: 0.37-0.98). The positive associations of the number of courses (OR 1.86; 95\% CI: 1.14-3.02) and the negative association of vaccination were 


\begin{tabular}{|c|c|c|c|c|c|}
\hline Predictors & B & SE & Beta & $P$-value & $95 \% \mathrm{Cl}$ for $\mathrm{B}$ \\
\hline \multicolumn{6}{|l|}{ Predictors of knowledge } \\
\hline Degree: MSD & 2.126 & 0.784 & 0.149 & 0.007 & 0.583 to 3.670 \\
\hline No. of courses: $\geq 3$ & 1.154 & 0.454 & 0.140 & 0.012 & 0.260 to 2.048 \\
\hline Use eye-shield: yes & 1.936 & 0.821 & 0.130 & 0.019 & 0.320 to 3.552 \\
\hline Preparation time for next patient: longer & 1.974 & 0.937 & 0.115 & 0.036 & 0.130 to 3.819 \\
\hline Self-confidence: very good & 1.868 & 0.559 & 0.183 & 0.001 & 0.769 to 2.967 \\
\hline \multicolumn{6}{|l|}{ Predictors of attitudes } \\
\hline Group practice: yes & 0.859 & 0.425 & 0.115 & 0.044 & 0.021 to 1.696 \\
\hline No. of courses: $\geq 3$ & 0.639 & 0.240 & 0.151 & 0.008 & 0.166 to 1.112 \\
\hline Use gloves: yes & 5.782 & 3.485 & 0.094 & 0.098 & -1.077 to 12.64 \\
\hline
\end{tabular}

All variables were initially modelled. Any variables not shown in the table were non-significant. $B=$ regression coefficient; $S E=$ standard error; $C I=$ confidence interval for the regression coefficient . $M S D=$ Master of science in dentistry.

again confirmed (OR 0.46; 95\% CI: $0.22-0.98)$. Better behaviour was associated with dentists working at dental offices that had unit preparation times $<3 \min$ (OR 0.56; 95\% CI: 0.32-0.97) (Table 5).

\section{Discussion}

The multivariable analyses of the study findings indicated that knowledge about hepatitis B was better among dentist who were MSD degree holders, academic faculty members, had taken more continuing education courses, used dental eye-shields, would put more time into preparing their dental units for each patient and had higher selfconfidence about their knowledge. A positive attitude towards people with $\mathrm{HBV}$ was more frequent in dentists attending more courses and those working in group practice clinics along with other dentists. The number of courses taken positively affected dentists' behaviour as well. Foreign-graduated dentists were more likely to reject $\mathrm{HBV}$-positive patients. A higher rate of willingness to accept HBV-positive patients was found in dentists practising at offices that prepared the unit for the next patient faster $(<3 \mathrm{~min})$.

Surprisingly, dentists who were immunized against HBV were about 2.5 times more likely to reject treatment for HBV-positive patients. On the other hand, a confirmed antibody titre improved dentists' willingness to treat patients about 2.3-fold. In view of the lack of any similar studies on risk factors for dentists' knowledge, attitude, and behaviour towards hepatitis B, we can only speculate about the explanation for this. Unvaccinated dentists might be less knowledgeable about the hazards of HBV and its cross-contamination or they might be risk-takers who care less about their own and their patients' safety. Dentists who are vaccinated might be more knowledgeable or more cautious and this might discourage them from delivering dental care to HBVpositive patients unless they are certain of their titre elevation after immunization. Hepatitis B vaccination can fail to produce proper levels of immunization and antibody titres need to be assessed $(3,17)$. Dentists should be taught that it is their antibody titre that matters, not

\begin{tabular}{lccccc}
\hline \multicolumn{7}{l}{ Table 3 Predictors of dentists' knowledge } & about hepatitis B virus & & & \\
\hline Predictors of knowledge & B & SE & Beta & P-value & $95 \%$ Cl for B \\
Sex: male & -0.765 & 0.862 & -0.051 & 0.376 & -2.461 to 0.931 \\
Age: older & 0.013 & 0.061 & 0.014 & 0.830 & -0.108 to 0.134 \\
Degree: MSD & 1.579 & 0.877 & 0.110 & 0.073 & -0.147 to 3.305 \\
Study origin: homeland & -1.678 & 0.970 & -0.096 & 0.085 & -3.586 to 0.231 \\
Experience: : $\geq 6$ yr & -1.245 & 1.169 & -0.067 & 0.288 & -3.547 to 1.056 \\
Faculty membership: yes & 2.137 & 1.070 & 0.123 & 0.047 & 0.031 to 4.244 \\
No. of courses: $\geq 3$ & 1.266 & 0.469 & 0.153 & 0.007 & 0.344 to 2.189 \\
Self-confidence: very good & 1.849 & 0.564 & 0.181 & 0.001 & 0.739 to 2.959
\end{tabular}

$B=$ regression coefficient; $S E=$ standard error; $C l=$ confidence interval for the regression coefficient. $M S D=$ Master of science in dentistry. 


\begin{tabular}{|c|c|c|c|}
\hline Predictors of behaviour & B & $P$-value & OR $(95 \% \mathrm{CI})$ \\
\hline Study origin: homeland & 0.73 & 0.032 & 2.08 (1.06 to 4.07$)$ \\
\hline No. of courses: $\geq 3$ & 0.76 & 0.005 & 2.15 (1.26 to 3.67$)$ \\
\hline Vaccinated: yes & -0.96 & 0.028 & 0.38 (0.16 to 0.90$)$ \\
\hline Titre check: yes & 0.84 & 0.002 & 2.31 (1.35 to 3.96$)$ \\
\hline
\end{tabular}

All variables were initially modelled. Any variables not shown in the table were non-significant.

$B=$ regression coefficient; $O R=$ odds ratio; $C I=$ confidence interval for the odds ratio.

only their vaccination status. Checking antibody status could be made mandatory, as it deals not only with dentists' health but also with prevention of crossinfection to patients (3).

Dentists' willingness to treat the simulated HBV-positive patients also increased with clinical experience (14). Attendance at postgraduate courses has been shown to improve dentists' willingness to treat AIDS patients (18), similar to our results for HBV. The number of continuing education courses attended by dentists was the only factor in our study that boosted all domains: knowledge, attitudes and behaviour. Taking continuing education courses is one of the major ways to remain licensed to practise dentistry in the Islamic Republic of Iran. However, there are other ways to remain licensed to work, such as attending conferences or taking part in certain journals' tests. After 5 years has elapsed since graduation, every dentist needs to do such activities annually to keep their licence. Dentists graduated in other countries (mostly Eastern Europe or Asia) had a tendency to reject HBV-positive patients. It seems that dentists who work or graduate in countries with higher risks of bloodborne or sexually transmitted infections need to be educated better through extra courses. This is confirmed by the positive effect of such courses on acceptance of HBV-positive patients, when other factors were held constant.

Interestingly, knowledge had no association with dentists' willingness to deliver dental care to a simulated HBVpositive patient. This is similar to studies on patients with HCV (19) and HIV (9), but contrasts with other research on HIV (20) and HCV (16). In line with the findings of another study on willingness to treat patients with AIDS (8), but in contrast to our own findings on AIDS patients (9), we found that working in a clinic with other dentists encouraged dentists to show more positive behaviour and attitudes towards HBV-positive patients. A longer period of work experience negatively affected United Kingdom dentists' attitudes (8) and Iranian dentists' attitudes and behaviour concerning AIDS patients (9). Nevertheless, it did not affect attitudes and behaviours related to treating HBV patients in this study. No other studies have assessed these factors in order for us to compare the results.

\section{Limitations and strengths}

Some constraints limited the current study. It is interesting that the variation

\begin{tabular}{|c|c|c|c|}
\hline Predictors of behaviour & B & $P$-value & OR $(95 \% \mathrm{CI})$ \\
\hline Degree: MSD & -0.508 & 0.042 & $0.60(0.37$ to 0.98$)$ \\
\hline Office: solo practice & 0.518 & 0.070 & 1.68 (0.96 to 2.94$)$ \\
\hline Office: group practice & 0.420 & 0.275 & $1.52(0.72$ to 3.23$)$ \\
\hline Faculty membership: yes & 0.337 & 0.274 & $1.40(0.77$ to 2.56$)$ \\
\hline No. of courses: $\geq 3$ & 0.620 & 0.012 & 1.86 (1.14 to 3.02$)$ \\
\hline Last course: $<2 \mathrm{yr}$ & -0.792 & 0.087 & 0.45 (0.18 to 1.12$)$ \\
\hline Last course: $\geq 2 \mathrm{yr}$ & -0.796 & 0.076 & 0.45 (0.19 to 1.09$)$ \\
\hline Unit preparation time: $\geq 3$ min & -0.583 & 0.039 & 0.56 (0.32 to 0.97$)$ \\
\hline Vaccinated: yes & -0.776 & 0.045 & $0.46(0.22$ to 0.98$)$ \\
\hline Titre check: yes & 0.369 & 0.132 & 1.45 (0.90 to 2.34$)$ \\
\hline Self-confidence: higher & -0.158 & 0.327 & 0.85 (0.62 to 1.17$)$ \\
\hline
\end{tabular}

All variables were initially modelled. Any variables not shown in the table were non-significant.

$B=$ regression coefficient; $S E=$ standard error; $C I=$ confidence interval for the odds ratio.

$M S D=$ Master of science in dentistry. 
of self-reported attitudes towards HBV was much narrower than the variability of behaviour towards actual patients. This implies that dentists' behaviour is affected by many uncontrollable factors, rather than merely reflecting their attitudes and beliefs. This indicates the need for direct observations instead of relying on self-declared attitudes in interviews.

An advantage of this study was that the multivariable models benefited from the inclusion of numerous different variables which allowed us to control for many confounders. Thus, the results are more reliable compared with the bivariate statistics used in previous studies on knowledge, attitudes and behaviour. However, the study design would be improved if some variables were assessed in more detail. For example, future studies should record dentists' work experience or the duration since last education course in years and not as dichotomized variables, as the latter discards useful details. It should be noted that the adjusted $R^{2}$ values were small, indicating that better models with larger samples and more controls are still needed.

The strengths and limitations of our simulated patient methods have been discussed in more detail in a previous article (9) and in the earlier paper on this same research (7). Another limitation of the survey methods was the method of assessing attitudes, since the interviews were face-to-face and dentists might have been biased towards giving more favourable answers, even though they had been told that their personal information would not be recorded. However, this limitation would not have affected responses to the knowledge or behaviour parts of the study.
To our knowledge this is the first study of knowledge, attitudes and behaviour towards HBV which did not rely on mass-survey methods. The generalizability of the findings might be limited by different practice requirements and public health policies of different countries regarding universal precautions and obligatory vaccination policies. For example, vaccination of dentists is obligatory in many countries but not in the Islamic Republic of Iran, although vaccination of dentists (and the general public) is encouraged because the vaccine is available free of charge. On the other hand, policies on universal precautions in Islamic Republic of Iran follow similar standards to many other countries and this favours the generalizability of the findings.

\section{Conclusions}

As expected, better knowledge was found among Master's degree holders, faculty members and dentists who had taken more courses, as well as those who used dental eye-shields and who put more time into preparing dental units, as well as dentists with higher self-confidence about their knowledge. Working in teams and attending more courses was associated with a better attitude towards patients with HBV. The number of courses also seemed to positively affect dentists' behaviour. Dentists graduated from the Islamic Republic of Iran were more willing to treat HBV-positive patients than were foreign-graduated dentists. Clinicians who worked in offices that needed a longer time for preparing the dental unit for the next patient were less likely to welcome patients. Interestingly, vaccination status alone did not facilitate the acceptance of HBVpositive patients (and in fact worsened the case). Thus, emphasis should be placed on antibody titre assessment, which was a factor contributing positively to dentists' acceptance of HBVpositive patients. Since the results of this and our previous study show that attending postgraduate courses can improve dentists' behaviour and attitudes, obligatory courses regarding hepatitis, AIDS and infection control for dentists can be recommended in the Islamic Republic of Iran, and as far as our results could be generalized to other countries, in other regions as well.

\section{Acknowledgements}

The authors sincerely thank colleagues who helped in different phases of this study, which was based on two DDS theses, the protocols of which were approved and registered as \#18066 and \#18067 by the internal review board of the University.

Authors' contributions: Behnam Khosravanifard conceived, designed, and supervised the study. Vahid Rakhshan was consulted regarding the study design, searched the literature, digitized the questionnaires, conceived the analysis of risk factors using multivariate statistics, designed and performed the statistical analyses, optimized the regression models, interpreted and discussed the findings, and drafted/ revised the article. Samira Sherafat and Leili Najafi-Salehi each interviewed the dentists, acted as a standardized patient, and calculated/digitized the scores.

Funding: The study was self-funded by the authors.

Competing interests: None declared

\section{References}

1. Mahboobi N, Agha-Hosseini F, Mahboobi N, Safari S, Lavanchy D, Alavian SM. Hepatitis B virus infection in dentistry: a forgotten topic. J Viral Hepat. 2010 May;17(5):307-16. PMID:20196802
2. Resende VL, Abreu MH, Paiva SM, Teixeira R, Pordeus IA. Concerns regarding hepatitis $B$ vaccination and post-vaccination test among Brazilian dentists. Virol J. 2010;7:154. PMID:20626908 
3. Kabir A, Tabatabaei SV, Khaleghi S, Agah S, Faghihi Kashani AH, Moghimi M, et al. Knowledge, attitudes and practice of Iranian medical specialists regarding hepatitis B and C. Hepat Mon. 2010 Summer;10(3):176-82. PMID:22308136

4. Ammon A, Reichart PA, Pauli G, Petersen LR. Hepatitis B and $\mathrm{C}$ among Berlin dental personnel: incidence, risk factors, and effectiveness of barrier prevention measures. Epidemiol Infect. 2000 Oct;125(2):407-13. PMID:11117965

5. Hepatitis B vaccines. Wkly Epidemiol Rec. 2009 Oct 1;84(40):405-19. PMID:19817017

6. Tirounilacandin P, Krishnaraj S, Chakravarthy K. Hepatitis-B infection: Awareness among medical, dental interns in India. Annals of Tropical Medicine and Public Health. 2009;2(2):33-36.

7. Khosravanifard B, Rakhshan V, Sherafat S, Salehi LN. Tehran dentists' knowledge of and attitude to hepatitis $B$ and willingness to treat hepatitis B patients as observed by simulated patients. East Mediterr Health J. 2014;20(8):498-507. PMID:25150357

8. Crossley ML. An investigation of dentists' knowledge, attitudes and practices towards HIV+ and patients with other bloodborne viruses in South Cheshire, UK. Br Dent J. 2004 Jun 26;196(12):749-54, quiz 780. PMID:15220975

9. Khosravanifard B, Rakhshan V, Ghasemi M, Pakdel A, Baradaran-Eghbal S, Sheikholeslami R, et al. Tehran dentists' selfreported knowledge and attitudes towards HIV/AIDS and observed willingness to treat simulated HIV-positive patients. East Mediterr Health J. 2012 Sep;18(9):928-34. PMID:23057385

10. Temple-Smith M, Jenkinson K, Lavery J, Gifford SM, Morgan M. Discrimination or discretion? Exploring dentists' views on treating patients with hepatitis C. Aust Dent J. 2006 Dec;51(4):31823. PMID:17256306

11. Singh A, Purohit BM, Bhambal A, Saxena S, Singh A, Gupta A. Knowledge, attitudes, and practice regarding infection control measures among dental students in Central India. J Dent Educ. 2011 Mar;75(3):421-7. PMID:21368266
12. Song KB, Choi KS, Lang WP, Jacobson JJ. Hepatitis B prevalence and infection control among dental health care workers in a community in South Korea. J Public Health Dent. 1999 Winter;59(1):39-43. PMID:11396043

13. Veronesi L, Bonanini M, Dall'Aglio P, Pizzi S, Manfiedi M, Tanzi ML. Health hazard evaluation in private dental practices: a survey in a province of northen Italy. Acta Biomed. 2004 Apr;75(1):50-5. PMID:15315087

14. Brailo V, Pelivan I, Škaricić J, Vuletić M, Dulcić N, Cerjan-Letica G. Treating patients with HIV and Hepatitis B and C infections: Croatian dental students' knowledge, attitudes, and risk perceptions. J Dent Educ. 2011 Aug;75(8):1115-26. PMID:21828306

15. Sears B. HIV discrimination in health care services in Los Angeles county: the results of three testing studies. Williams Institute study. Los Angeles (CA): The Williams Institute; 2006 (http:// www.bc.edu/content/dam/files/schools/law_sites/library/ pdf/content/tremblay_schulman/2006-12-00.Sears_Ho.pdf, accessed 19 October 2014).

16. Richmond JA, Dunning TL, Desmond PV. Health professionals' attitudes toward caring for people with hepatitis C. J Viral Hepat. 2007 Sep;14(9):624-32. PMID:17697014

17. Lasemi E, Haddadpour N, Navi F, Rakhshan A, Rakhshan V. Rate of acquired immunity in dental students after hepatitis B vaccination. Dent Res J (Isfahan). 2011 Summer;8(3):128-31. PMID:22013475

18. Wilson NH, Burke FJ, Cheung SW. Factors associated with dentists' willingness to treat high-risk patients. Br Dent J. 1995 Feb 25;178(4):145-8. PMID:7893547

19. van de Mortel TF. Health care workers' knowledge of hepatitis $\mathrm{C}$ and attitudes towards patients with hepatitis C: a pilot study. Aust J Adv Nurs. 2002 Sep-Nov;20(1):13-9. PMID:12405278

20. Kitaura H, Adachi N, Kobayashi K, Yamada T. Knowledge and attitudes of Japanese dental health care workers towards HIV-related disease. J Dent. 1997 May-Jul;25(3-4):279-83. PMID:9175358 